\title{
miR-221 targets HMGA2 to inhibit bleomycin-induced pulmonary fibrosis by regulating TGF-ß31/Smad3-induced EMT
}

\author{
YI-CHUN WANG ${ }^{1,2}$, JING-SHI LIU ${ }^{2}$, HAO-KE TANG ${ }^{3}$, JING NIE $^{2}$, \\ JI-XIAN ZHU ${ }^{2}$, LING-LING WEN ${ }^{2}$ and QU-LIAN GUO ${ }^{1}$ \\ ${ }^{1}$ Department of Anesthesiology, Xiangya Hospital, Central South University, Changsha, Hunan 410008; \\ Departments of ${ }^{2}$ Critical Care Medicine and ${ }^{3}$ Hospice and Palliative Care, The Affiliated Cancer Hospital \\ of Xiangya Medical School, Central South University, Changsha, Hunan 410013, P.R. China
}

Received September 1, 2015; Accepted July 22, 2016

DOI: $10.3892 /$ ijmm.2016.2705

\begin{abstract}
MicroRNA (miR)-221 plays an essential role in the epithelial-mesenchymal transition (EMT). High mobility group AT-hook 2 (HMGA2), is a key regulator of EMT. However, the role of miR-221 in pulmonary fibrosis, and the association between miR-221 and HMGA2 remain largely unknown. For this purpose, we examined the expression of miR-221 and HMGA2 in human idiopathic pulmonary fibrosis (IPF) tissues and pulmonary cells, namely the adenocarcinoma A549 and human bronchial epithelium (HBE) cell lines, and found that the expression of miR-221 was inhibited in both tissues and cells whereas high mRNA and protein expression of HMGA2 was observed. Additionally, transforming growth factor- $\beta 1$ (TGF- $\beta 1$ ) induced the EMT, characterized by the upregulated expression of the mesenchymal markers, namely $\mathrm{N}$-cadherin, vimentin, $\alpha$-smooth muscle actin, collagen I and collagen III, and the downregulated expression of the epithelial marker E-cadherin in A549 and HBE cells. We then performed transfection with miR-221 mimics, and found that the expression of phosphorylated-Smad3 in miR-221-overexpressing cells was significantly downregulated, compared with that in the TGF- $\beta 1$-treated cells without transfection. Furthermore, the overexpression of miR-221 decreased the expression of HMGA2, suppressed the EMT, and inhibited the proliferation of A549 and HBE cells. HMGA2 was directly targeted by miR-221 which was confirmed by the dual-luciferase reporter gene assay. Finally, a mouse model of bleomycin (BLM)-induced pulmonary fibrosis was used to confirm the effect of miR-221 on EMT. Hematoxylin and eosin staining showed that BLM induced thicker alveolar walls and more collagen deposition, whereas miR-221 treatment reduced lung fibrosis and the tissues exhibited thinner alveolar
\end{abstract}

Correspondence to: $\mathrm{Dr}$ Qu-Lian Guo, Department of Anesthesiology, Xiangya Hospital, Central South University, 87 Xiangya Road, Changsha, Hunan 410008, P.R. China

E-mail: guoqulian_xy@sina.com

Key words: microRNA-221, epithelial-mesenchymal transition, high mobility group AT-hook 2, bleomycin-induced pulmonary fibrosis, transforming growth factor- $\beta 1$ walls and normal lung alveoli. Furthermore, the EMT process was suppressed following miR-221 injection. Taken together, these findings sugest that miR-221 targets HMGA2 to inhibit BLM-induced pulmonary fibrosis through the TGF- $\beta 1 /$ Smad3 signaling pathway.

\section{Introduction}

Idiopathic pulmonary fibrosis (IPF) is an aggressive disease that involves the replacement of normal lung parenchyma with fibrotic tissue in combination with inflammation, fibroblast proliferation, and excessive collagen deposition (1). Epithelial-mesenchymal transition (EMT), which is characterized by the loss of epithelial characteristics (E-cadherin) and the acquisition of a mesenchymal phenotype [ $\mathrm{N}$-cadherin, vimentin, and $\alpha$-smooth muscle actin ( $\alpha$-SMA)] (3), is a major contributor to the pathogenesis of fibrosis (4). Accordingly, it is necessary to better understand the process of EMT in order to develop novel therapeutic strategies for IPF (5). As a well-established inducer of EMT (6-8), the increased expression of transforming growth factor- $\beta 1$ (TGF- $\beta 1$ ) has been suggested to lead to tissue fibrosis in many organs, including the lung (9-12). Moreover, the inhibition of TGF- $\beta 1 / \mathrm{Smad} 3$ signaling has been reported to ameliorate fibrosis, validating the TGF- $\beta 1 / \mathrm{Smad} 3$ signaling pathway as a therapeutic target for the treatment of lung fibrosis (13-15). High mobility group AT-hook 2 (HMGA2), a transcription factor that is induced by the TGF- $\beta 1 /$ Smad 3 signaling pathway during the EMT process (3), is also reported to promote EMT (2) and to be upregulated in IPF (3).

MicroRNAs (miRNAs or miRs) are a type of small, non-coding RNAs which regulate protein expression by either inhibiting translation or initiating the specific degradation of target mRNAs (16). Previous studies suggest that miRNA regulation is critical in the process of EMT and pulmonary fibrosis. For example, members of the miR-200 family and miR-205 are decreased when cells undergo EMT (17). miR-124 targets Slug to regulate EMT and promote the metastasis of breast cancer (18). The increased expression of miR-155 has been found in a mouse model of lung fibrosis (19). Liu et al have demonstrated that mice with bleomycin (BLM)-induced pulmonary fibrosis exhibited a significant increase in miR-21 levels, which was 
associated with an increased TGF- $\beta$ level (20). Additionally, the decreased expression of members of the miR-29 family is also found in the lungs of patients with IPF compared with normal individuals (21). Accordingly, miRNAs merit further evaluation as a therapeutic target in pulmonary fibrosis.

miR-221 is reported not only to induce EMT in pancreatic cancer (22), breast cancer (23) and bladder cancer (24), but it is also associated with kidney fibrosis (25) and liver fibrosis (26). However, whether miR-221 plays a role in pulmonary fibrosis as well as the target of miR-221 in the EMT process remain largely unknown. In this study, we first detected the expression of miR-221 and HMGA2 in human IPF tissue and cells. The expression of EMT-related proteins in human bronchial epithelium (HBE) cells and adenocarcinoma A549 cells was detected following TGF- $\beta 1$ treatment. Following the transfection of miR-221 mimics, the expression of Smad3, phosphorylated (p-) Smad3 and HMGA2 was detected. EMT and cell proliferation were also evaluated in miR-221-overexpressing cells. The association between miR-221 and HMGA2 was confirmed by a dual-luciferase reporter gene assay. Finally, a model of BLM-induced pulmonary fibrosis was used in order to examine the protective effects of miR-221 in EMT. These findings may provide novel insights into the treatment of pulmonary fibrosis.

\section{Materials and methods}

Isolation of human lung tissue. A total of 10 human IPF tissues and the corresponding adjacent normal tissues were obtained from surgical remnants of biopsies or lungs explanted from patients with IPF that underwent pulmonary transplantation. This study was approved by the Ethics Committee of Central South University (Changsha, China). All patients provided written informed consent for the use of their samples in scientific research.

Cell culture. The HBE and adenocarcinoma A549 cell lines were purchased from Auragene Bioscience Co. (Changsha, China). The cells were cultured in Dulbecco's modified Eagle's medium (Hyclone, Logan, UT, USA) supplemented with $10 \%$ fetal calf serum (Gibco BRL, Gaithersburg, MD, USA). TGF- $\beta 1$ (Sigma-Aldrich, St. Louis, MO, USA) was used at final concentration of $10 \mathrm{ng} / \mathrm{ml}$. The cells were cultured in medium containing TGF- $\beta 1$ for $48 \mathrm{~h}$, and then collected for further analysis.

Transfection. The A549 and HBE cells were cultured as described above prior to transfection. A total of $100 \mathrm{pmol}$ of either mimics NC, miR-221 mimics, inhibitor NC or miR-221 inhibitor (Auragene Bioscience Co.) was diluted in $250 \mu 1$ serum-free RPMI-1640 medium, which was then mixed with $10 \mu$ l Lipofectamine ${ }^{\circledR} 2000$ (diluted in $250 \mu$ l serum-free medium). After incubation at $37^{\circ} \mathrm{C}$ for $4 \mathrm{~h}$, the medium was replaced with complete medium and cultured for a further $48 \mathrm{~h}$. The cells were then collected for use in subsequent experiments.

MTT assay. For proliferation analysis of A549 and HBE cells, 5,000 cells were plated in three 96-well plates. At 24, 48 and $72 \mathrm{~h}$, the cells in one plate were treated with $20 \mu \mathrm{l}$ MTT solution $(5 \mathrm{mg} / \mathrm{ml})$ for $4 \mathrm{~h}$. Subsequently, MTT solution was replaced with $150 \mu \mathrm{l}$ dimethylsulfoxide (DMSO) to dissolve the tetrazolium crystals. After $10 \mathrm{~min}$, the optical density values were read at a test wavelength of $570 \mathrm{~nm}$ with a microplate reader (Thermo Labsystems, Altrincham, UK).

Reverse transcription-quantitative polymerase chain reaction (RT-qPCR). Total RNA was extracted from cells and tissues using TRIzol reagent (Life Technologies, Shanghai, China) according to the manufacturer's instructions. cDNA was synthesized with a TaqMan MicroRNA Reverse Transcription kit (Applied Biosystems Life Technologies, Foster City, CA, USA). qPCR was performed using a Lightcycler ${ }^{\circledR} 480$ SYBRGreen I Master system (Roche, Mannheim, Germany) according to the manufacturer's instructions. $\beta$-actin was used as an internal control. The following primer sequences were used: miR-221 (HmiRQP0337) and U6 (HmiRQP9001) (both from Fulengen, Guangzhou, China); HMGA2 sense, TGTGGCCA ATGGAACAGTAA and antisense, CGACCAACAACAG CAAAGAA; TGF- $\beta 1$ sense, CGAGCCTGAGGCCGAC TACTA and antisense, CTCGGAGCTCTGATGTGTTGAA; collagen III sense, TGATGGGATCCAATGAGGGAGA and antisense, GAGTCTCATGGCCTTGCGTGTTT; collagen I sense, ATCAGCCCAAACCCCAAGGAGA and antisense, CGCAGGAAGGTCAGCTGGATAG; E-cadherin sense, CAT TTCCCAACTCCTCTCCTGGC and antisense, ATGGGCCT TTTTCATTTTCTGGG; N-cadherin sense, CCACGCCG AGCCCCAGTATC and antisense, CCCCCAGTCGTTCAG GTAATCA; vimentin sense, GACGCCATCAACACCGAGTT and antisense, CTTTGTCGTTGGTTAGCTGGT; $\alpha$-SMA sense, AGAAGCCCAGCCAGTCGCCATCA and antisense, AGCAAAGCCCGCCTTACAGAGCC; $\beta$-actin sense, AGG GGCCGGACTCGTCATACT and antisense, GGCGGCAC CACCATGTACCCT. PCR was performed in a total volume of $20 \mu \mathrm{l}$, including $10 \mu \mathrm{l}$ of $2 \mathrm{X}$ SYBR-Green qPCR Mix, $1 \mu \mathrm{l}$ of each forward and reverse primer $(10 \mu \mathrm{mol} / \mathrm{l}), 1 \mu \mathrm{l}$ of each cDNA sample and $7 \mu \mathrm{H}_{2} \mathrm{O}$. Amplifications were performed in triplicate in 96-well microtiter plates. The thermal cycling conditions were as follows: $95^{\circ} \mathrm{C}$ for $3 \mathrm{~min}$, followed by 35 cycles of $95^{\circ} \mathrm{C}$ for $10 \mathrm{sec}$, and $60^{\circ} \mathrm{C}$ for $30 \mathrm{sec}$, finally followed by $95^{\circ} \mathrm{C}$ for $12 \mathrm{sec}$ and $60^{\circ} \mathrm{C}$ for $50 \mathrm{sec}$.

Western blot analysis. Lysates of whole-cell or tissue homogenate were lysed in a buffer containing $150 \mathrm{mM} \mathrm{NaCl}, 1 \mathrm{mM}$ phenymethylsulfonyl fluoride, $\mathrm{NaVO}_{4}$, aprotinin and leupeptin as protease inhibitors, $50 \mathrm{mM}$ Tris- $\mathrm{HCl} \mathrm{pH} 8.0,0.2 \%$ sodium dodecyl sulphate (SDS), $1 \%$ NP-40. Protein (30 $\mu \mathrm{g} / \mathrm{sample})$ was resolved on a SDS-polyacrylamide gel with subsequent transfer blotting. The membranes were incubated at $4^{\circ} \mathrm{C}$ with the following primary antibodies overnight: HMGA2 (ab97276; Abcam, Cambridge, UK); E-cadherin (YT1453; ImmunoWay Biotechnology Company, Newark, DE, USA); N-cadherin (ab18203; Abcam); vimentin (YT4881) and $\alpha$-SMA (YT5053) both from ImmunoWay Biotechnology Company); collagen I (ab34710) and collagen III (ab7778) (both from Abcam); TGF- $\beta 1$ (YT4632; ImmunoWay Biotechnology Company); Smad3 (\#9513s; Cell Signaling Technology, Danvers, MA, USA); and p-smad3 (sc-130218; Santa Cruz Biotechnology, Inc., Dallas, TX, USA). After washing, the membranes were incubated with the corresponding secondary antibody (111-035-003 or 111-035-008; Jackson ImmunoResearch Laboratories, Inc., West Grove, PA, USA) for $1 \mathrm{~h}$ at room temperature, followed by chemiluminescence for visualization. 

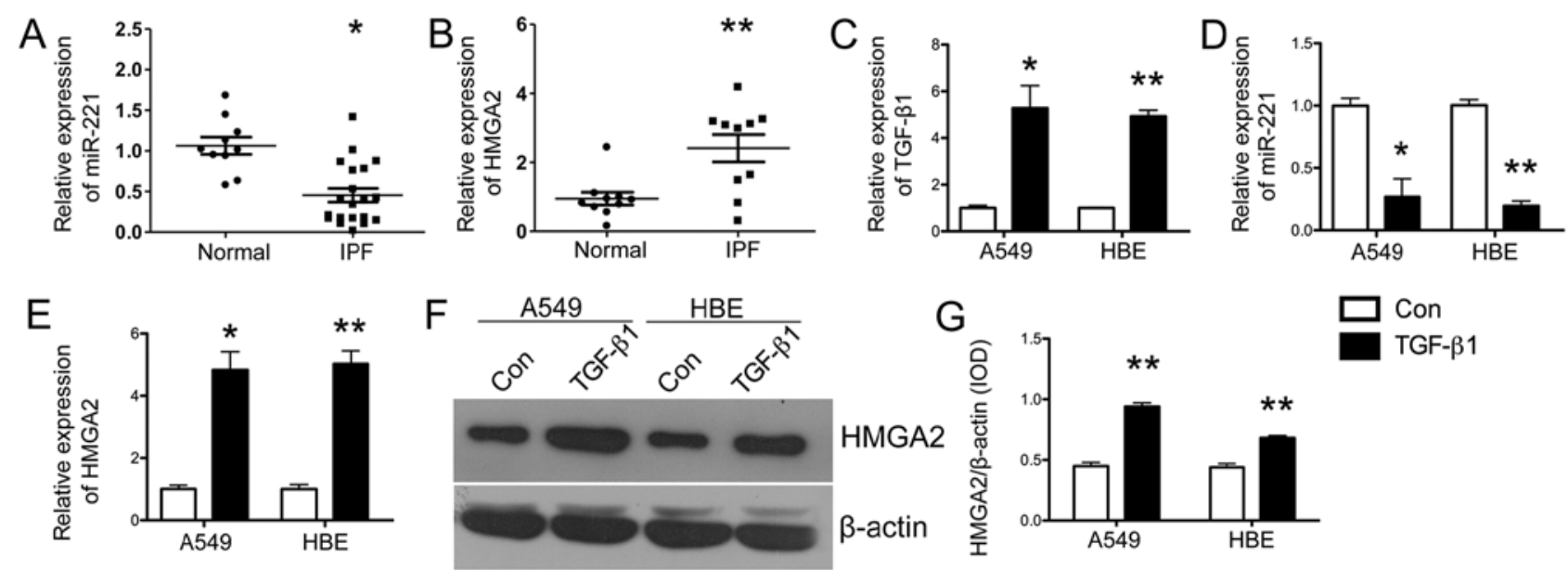

Figure 1. Expression of miR-221 and high mobility group AT-hook 2 (HMGA2) in human idiopathic pulmonary fibrosis (IPF) tissues and human pulmonary cells [A549 and human bronchial epithelium (HBE) cell lines]. Statistical analysis of the mRNA expression of (A) miR-221 and (B) HMGA2 in normal human lung tissues and IPF tissues detected by qPCR. Data are presented as the means $\pm \mathrm{SD}, \mathrm{n}=10 .{ }^{*} \mathrm{P}<0.05 ;{ }^{* *} \mathrm{P}<0.01 ;{ }^{* * *} \mathrm{P}<0.001$. A549 and HBE cells were used for in vitro research. Cells were first stimulated with transforming growth factor- $\beta 1$ (TGF- $\beta 1$ ) for $48 \mathrm{~h}$. The mRNA expression of (C) TGF- $\beta 1$, (D) miR-221 and (E) HMGA2 in A549 and HBE cells was measured by qPCR. (F) Representative western blot showing the protein expression of HMGA2. (G) Statistical analysis of HMGA2 protein expression in A549 and HBE cells. Data are presented as the means $\pm \mathrm{SD}, \mathrm{n}=3 .{ }^{*} \mathrm{P}<0.05 ;{ }^{* * *} \mathrm{P}<0.01$.

miRNA target prediction. The miRNA target prediction software, microRNA.org-Targets and Expression, was used to identify potential miR-221 targets.

Dual-luciferase reporter gene assay. A dual-luciferase reporter gene assay kit (E1910; Promega Corp., Madison, WI, USA) was used in the experiment. A 3'-untranslated region (3'-UTR) segment of the HMGA2 gene was amplified by PCR. The PCR products were recombined with psi-CHECK2. A549 and HBE cells were transfected with the firefly luciferase HMGA2-3'-UTR-psi-CHECK2, combined with miR-221 mimics (HmiR-AN0337), miR-221 inhibitor (HmiR-AN0337-SN-10), miRNA negative control (NC) mimics (CmiR-AN0001) and miRNA NC inhibitor (CmiR-AN0001-SN) (all from Fulengen), respectively. Twenty-four hours after transfection, the cells were lysed with a $1 \mathrm{X}$ passive lysis buffer and the activity of both Renilla and firefly luciferase was assayed using the dual-luciferase reporter assay system (Promega Corp.) according to the manufacturer's instructions.

Establishment of a mouse model of BLM-induced pulmonary fibrosis. A total of 35 8-week-old male BALB/c mice were purchased from the Slaccas Experimental Animal Company (Shanghai, China). All animal experiments were carried out after obtaining approval from the Ethics Committee of Central South University. The mice were divided into the following 4 groups: i) control, ii) BLM, iii) BLM + pre-Con, and iv) BLM + pre-miR-221. For BLM (Hisun Pfizer Pharmaceuticals Co., Ltd., Zhejiang, China) treatment, 8 -week-old mice were anesthetized with isoflurane. BLM (10 $\mathrm{mg} / \mathrm{kg}$ body weight in $50 \mu \mathrm{l}$ saline) was delivered into the oropharyngeal cavity after the tongues of the anesthetized mice were gently pulled forward. The tongue was kept in an extended position until intratracheal injection was complete. The control group without BLM treatment was injected with saline whereas the BLM group was without injection. The other 2 groups were injected with the mimics $\mathrm{NC}$ and miR-221 mimics $(10 \mathrm{mg} / \mathrm{kg})$, respectively. Saline and the mimics were injected intratracheally. The mice were sacrificed after 28 days, and the lung tissue was used for subsequent analysis.

Hematoxylin and eosin $(H \& E)$ staining. The assay was performed by the UAB Tissue Histology Core Facility as described previously (27).

Statistical analysis. All data are presented as the means \pm standard deviation (SD). Comparisons among groups were performed by one-way ANOVA using SPSS 17.0 software (SPSS, Inc., Chicago, IL, USA). All experiments were repeated three times. $\mathrm{P}<0.05$ was considered to indicate a statistically significant difference.

\section{Results}

miR-221 expression is downregulated and HMGA2 expression is upregulated both in vivo and in vitro. To detect the expression of miR-221 and HMGA2 in human IPF tissue, 10 samples of human IPF tissue and adjacent normal tissue were collected and analyzed by qPCR, respectively. As shown in Fig. 1A, miR-221 expression in the IPF tissues was significantly downregulated compared with that in the adjacent normal tissues $(\mathrm{P}=0.025)$. Notably, the relative expression of HMGA2 in the IPF tissues was significantly higher than that in the adjacent normal tissues ( $\mathrm{P}=0.001$, Fig. 1B).

Additionally, we examined miR-221 and HMGA2 expression in adenocarcinoma A549 cells and HBE cells following TGF- $\beta 1$ treatment. As shown in Fig. 1C, the mRNA expression of TGF- $\beta 1$ in both A549 and HBE cells was significantly increased (A549, $\mathrm{P}=0.017$; HBE, $\mathrm{P}=0.009$ ). miR-221 expression was significantly downregulated (A549, $\mathrm{P}=0.019$; HBE, $\mathrm{P}=0.002$; Fig. 1D) whereas HMGA2 was highly expressed in the cells following TGF- $\beta 1$ treatment (A549, $\mathrm{P}=0.011$; HBE, $P=0.002$; Fig. 1E). Furthermore, the expression of 

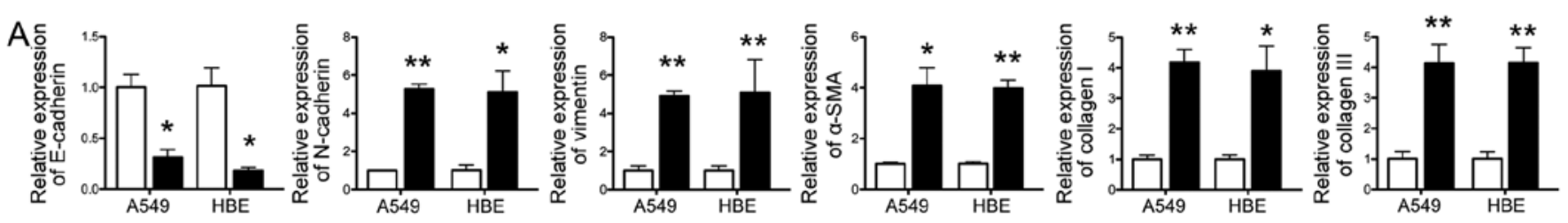

B

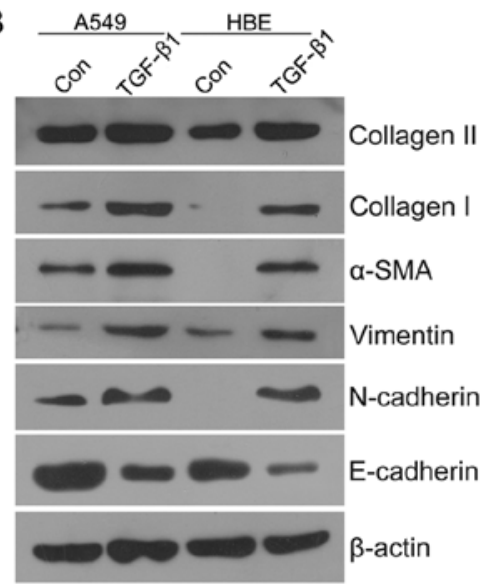

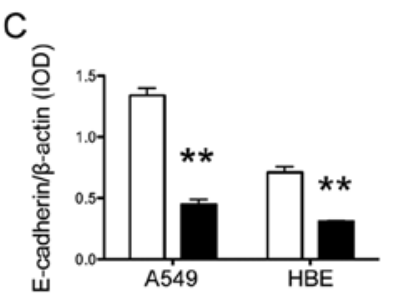
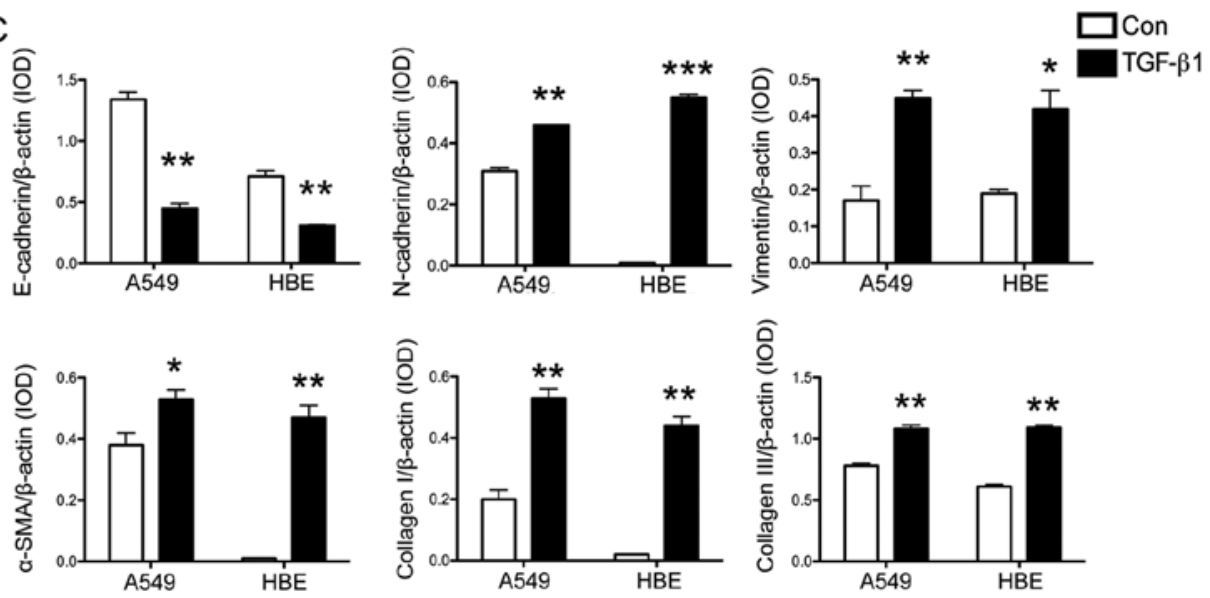

Figure 2. Transforming growth factor- $\beta 1$ (TGF- $\beta 1$ ) induces the epithelial-mesenchymal transition in A549 and human bronchial epithelium (HBE) cells. (A) The relative mRNA expression of E-cadherin, N-cadherin, vimentin, $\alpha$-smooth muscle actin ( $\alpha$-SMA), collagen I and collagen III in A549 and HBE cells was evaluated by qPCR. The cells without TGF- $\beta 1$ treatment were used as the control group. (B) Representative western blot showing the protein expression of E-cadherin, N-cadherin, vimentin, $\alpha$-SMA, collagen I and collagen III in A549 and HBE cells. (C) Statistical analysis of the protein expression of E-cadherin, $\mathrm{N}$-cadherin, vimentin, $\alpha$-SMA, collagen I and collagen III in A549 and HBE cells. Data are presented as the means $\pm \mathrm{SD}, \mathrm{n}=3 .{ }^{*} \mathrm{P}<0.05 ;{ }^{* *} \mathrm{P}<0.01 ;{ }^{* * *} \mathrm{P}<0.001$.

HMGA2 in A549 and HBE cells was evaluated by western blot analysis (Fig. 1F). The protein expression of HMGA2 was significantly upregulated in both cell types (A549, $\mathrm{P}=0.002$; HBE, $\mathrm{P}=0.003$; Fig. 1G). Collectively, these findings indicate that miR-221 was downregulated both in IPF tissues and in A549 and HBE cells whereas HMGA2 expression was upregulated.

TGF- $\beta 1$ induces the EMT in A549 and HBE cells. EMT is characterized by the loss of the epithelial cell marker E-cadherin and the increased expression of the mesenchymal markers $\mathrm{N}$-cadherin, vimentin and $\alpha$-SMA as well as the associated deposition of collagens. qPCR and western blot analysis were performed to evaluate the expression of E-cadherin, $\mathrm{N}$-cadherin, vimentin, $\alpha$-SMA, collagen I and collagen III in A549 and HBE cells. The qPCR data showed that N-cadherin (A549, $\mathrm{P}=0.003$; HBE, $\mathrm{P}=0.033$ ), vimentin ( $\mathrm{A} 549, \mathrm{P}=0.004$; HBE, $\mathrm{P}=0.009$ ), $\alpha$-SMA (A549, $\mathrm{P}=0.019$; HBE, $\mathrm{P}=0.002$ ), collagen I (A549, $\mathrm{P}=0.008 ; \mathrm{HBE}, \mathrm{P}=0.028$ ) and collagen III (A549, $\mathrm{P}=0.008 ; \mathrm{HBE}, \mathrm{P}=0.003$ ) were significantly increased whereas E-cadherin (A549, $\mathrm{P}=0.01$; $\mathrm{HBE}, \mathrm{P}=0.021)$ expression was significantly decreased (Fig. $2 \mathrm{~A}$ ) in the TGF- $\beta 1$-treated group compared with the control group. Western blot analysis revealed that TGF- $\beta 1$ had similar effects on the expression of E-cadherin (A549, $\mathrm{P}=0.002$; HBE, $\mathrm{P}=0.003$ ), $\mathrm{N}$-cadherin (A549, $\mathrm{P}=0.001$; HBE, $\mathrm{P}=0.000)$, vimentin (A549, $\mathrm{P}=0.003$; HBE, $\mathrm{P}=0.017$ ), $\alpha$-SMA (A549, $\mathrm{P}=0.048$; HBE, $\mathrm{P}=0.002$ ), collagen I (A549, $\mathrm{P}=0.009 ; \mathrm{HBE}, \mathrm{P}=0.002)$ and collagen III (A549, $\mathrm{P}=0.001 ; \mathrm{HBE}, \mathrm{P}=0.002$ ) as those observed in qPCR (Fig. 2B and C). Taken together, these findings demonstrate that TGF- $\beta 1$ induced the EMT in A549 and HBE cells.
Overexpression of miR-221 suppressed the TGF- $\beta 1 /$ Smad3 signaling pathway in vitro. The effect of $\mathrm{miR}-221$ on the activation of TGF- $\beta 1 /$ Smad3 signaling pathway was evaluated by western blot analysis. The protein expression of p-Smad3 in A549 and HBE cells was significantly upregulated following TGF- $\beta 1$ treatment (A549, $\mathrm{P}=0.002$; HBE, $\mathrm{P}=0.001$ ), whereas no changes were observed in Smad3 expression (A549, $\mathrm{P}=0.065 ; \mathrm{HBE}, \mathrm{P}=0.073$; Fig. $3 \mathrm{~A}$ and $\mathrm{B})$. This indicates that TGF- $\beta 1 / \mathrm{Smad} 3$ signaling was activated by TGF- $\beta 1$ in both cell types.

Additionally, we performed gain-of-function studies using miR-221 mimics, and miRNA transfection efficiency was determined by qPCR. Following the transfection of A549 and HBE cells with miR-221 mimics, miR-221 expression was significantly upregulated (A549, $\mathrm{P}=0.004$; HBE, $\mathrm{P}=0.001$; Fig. 3C). However, the results of western blot analysis (Fig. 3D) revealed a significant decrease in the protein expression of $\mathrm{p}-\mathrm{Smad} 3$ in both types of miR-221-overexpressed cells (A549, $\mathrm{P}=0.000$; $\mathrm{HBE}, \mathrm{P}=0.000$ ), with no difference in $\mathrm{Smad} 3$ protein expression (A549, $\mathrm{P}=0.074$; HBE, $\mathrm{P}=0.064$; Fig. 3E). These findings conclusively demonstrate that miR-221-overexpressing cells suppressed the activation of the TGF- $\beta 1 / \mathrm{Smad} 3$ signaling pathway.

Overexpression of miR-221 downregulates HMGA2 expression, suppresses the EMT and inhibits cell proliferation. Following the transfection of miR-221 mimics, the expression of HMGA2 was evaluated by qPCR and western blot analysis. The relative expression of HMGA2 was downregulated after overexpression of miR-221 (A549, $\mathrm{P}=0.013$; HBE, $\mathrm{P}=0.001$; Fig. 4A). Western blot analysis revealed similar results to those observed in the $\mathrm{qPCR}$ results (A549, $\mathrm{P}=0.001$; HBE, $\mathrm{P}=0.001$; Fig. 4B and $\mathrm{C}$ ). 

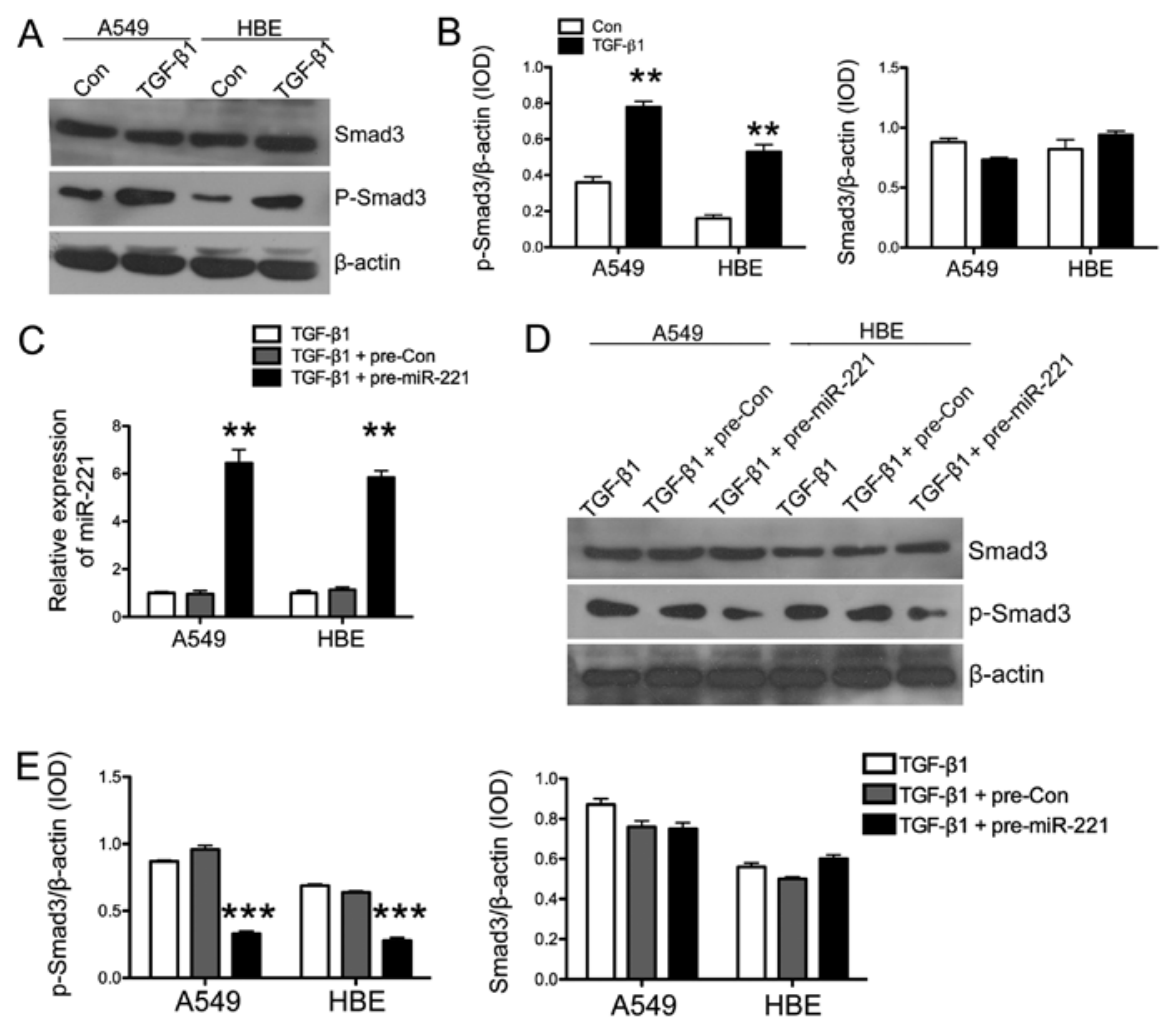

Figure 3. Overexpression of miR-221 suppresses the activation of the transforming growth factor- $\beta 1$ (TGF- $\beta 1$ )/Smad3 signaling pathway. (A) Representative western blot showing the protein expression of Smad3 and phosphorylated (p-)Smad3 in A549 and human bronchial epithelium (HBE) cells treated with TGF- $\beta 1$ for $48 \mathrm{~h}$. The cells without any treatment was used as the control group. (B) Statistical analysis of the protein expression of Smad3/p-Smad3 in A549 and HBE cells. (C) The relative expression of miR-221 in A549 and HBE cells following transfection with miR-221 mimics or mimics NC was detected by qPCR. (D) Representative western blot showing the protein expression of Smad3 and p-Smad3 in A549 and HBE cells with or without transfection. (E) Statistical analysis of the protein expression of Smad3 and p-Smad3 in A549 and HBE cells. Data are presented as the means \pm standard deviation, $\mathrm{n}=3$. ${ }^{* *} \mathrm{P}<0.01$; ${ }^{* * *} \mathrm{P}<0.001$.

qPCR and western blot analysis were then used to evaluate the effect of miR-221 overexpression on EMT regulation. As shown in Fig. 4D, the expression of N-cadherin (A549, $\mathrm{P}=0.042$; HBE, $\mathrm{P}=0.014$ ), vimentin (A549, $\mathrm{P}=0.000$; HBE, $\mathrm{P}=0.034), \alpha$-SMA (A549, $\mathrm{P}=0.007$; HBE, $\mathrm{P}=0.001$ ), collagen I (A549, $\mathrm{P}=0.017$; HBE, $\mathrm{P}=0.006$ ) and collagen III (A549, $\mathrm{P}=0.016 ; \mathrm{HBE}, \mathrm{P}=0.005$ ) was significantly decreased, whereas E-cadherin expression(A549, $\mathrm{P}=0.042$; HBE, $\mathrm{P}=0.049$ ) was significantly increased following transfection with miR-221 mimics, compared with the control group. The results of western blot analysis showed that miR-221 overexpression had similar effects on the expression of E-cadherin (A549, $\mathrm{P}=0.005$; HBE, $\mathrm{P}=0.012$ ), $\mathrm{N}$-cadherin (A549, $\mathrm{P}=0.000$; HBE, $\mathrm{P}=0.002$ ), vimentin (A549, $\mathrm{P}=0.011$; HBE, $\mathrm{P}=0.010$ ), $\alpha$-SMA (A549, $\mathrm{P}=0.000$; HBE, $\mathrm{P}=0.007$ ), collagen I (A549, $\mathrm{P}=0.032$; HBE, $\mathrm{P}=0.002$ ) and collagen III (A549, $\mathrm{P}=0.001$; HBE, $\mathrm{P}=0.003$ ) as in $\mathrm{qPCR}$ (Fig. 4E and F). Taken together, these findings demonstrate that miR-221 overexpression suppressed the EMT in A549 and HBE cells.

Additionally, the effects of upregulating miR-221 on the proliferation of A549 and HBE cells were examined by MTT assay. Transfection of miR-221 mimics led to a significant decrease in the proliferation of A549 $(\mathrm{P}<0.01)$ and HBE $(\mathrm{P}<0.01)$ cells, and the anti-miR-221 group exhibited a significant increase in the proliferation of A549 $(\mathrm{P}<0.01)$ and HBE $(\mathrm{P}<0.05)$ cells (Fig. 4G). These data indicate that miR-221 plays a vital role in reducing the EMT in vitro.
miR-221 directly targets HMGA2 and downregulates the expression of HMGA2 in A549 and HBE cells. The bioinformatics tool, microRNA.org-Targets and Expression, was used to predict the targets for miR-221. HMGA2 was identified as a potential target of miR-221. Additionally, a dual-luciferase reporter gene assay was performed to examine whether HMGA2 was functionally targeted by miR-221. Fig. 5A shows that overexpression of miR-221 inhibited luciferase activity from the construct with the HMGA2-3'-UTR segment in both A549 $(\mathrm{P}=0.026)$ and HBE cells $(\mathrm{P}=0.011)$. No changes were observed in luciferase reporter activity when the cells were transfected with anti-miR-221 or the controls. This demonstrates that HMGA2 was a direct target of miR-221 in A549 and HBE cells.

In addition, we performed qPCR and western blot analysis to evaluate the expression of HMGA2 following the transfection of A549 and HBE cells with pre-miR-221 or anti-miR-221 mimics. As shown in Fig. 5B, pre-miR-221 significantly increased miR-221 expression (A549, $\mathrm{P}=0.022$; HBE $\mathrm{P}=0.020$ ), and anti-miR-221 decreased miR-221 expression (A549, $\mathrm{P}=0.006$; HBE, $\mathrm{P}=0.009$ ). By contrast, HMGA2 mRNA expression was downregulated in the pre-miR-221 group (A549, $\mathrm{P}=0.025$; HBE $\mathrm{P}=0.012)$ and upregulated in the anti-miR-221 group (A549, $\mathrm{P}=0.010$; HBE, $\mathrm{P}=0.032$; Fig. 5C). The results of western blot analysis showed similar effects as miR-221 overexpression downregulated the expression of HMGA2 (pre-miR-221: A549, $\mathrm{P}=0.007$; HBE, $\mathrm{P}=0.001$; anti-miR-221: A549, $\mathrm{P}=0.003$; HBE, $\mathrm{P}=0.000$ ) as in $\mathrm{qPCR}$ (Fig. 5D and $\mathrm{E}$ ). 
A

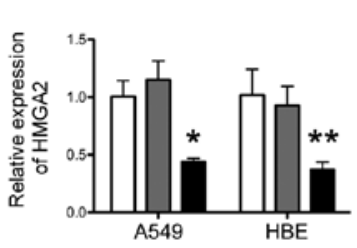

B

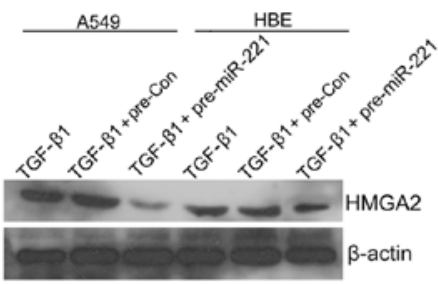

C

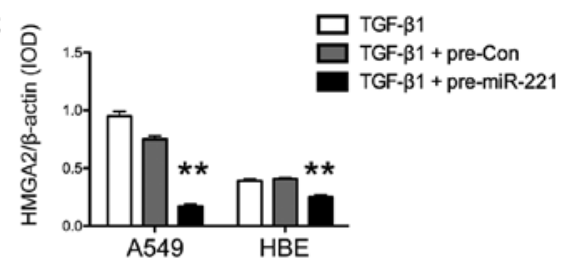

E
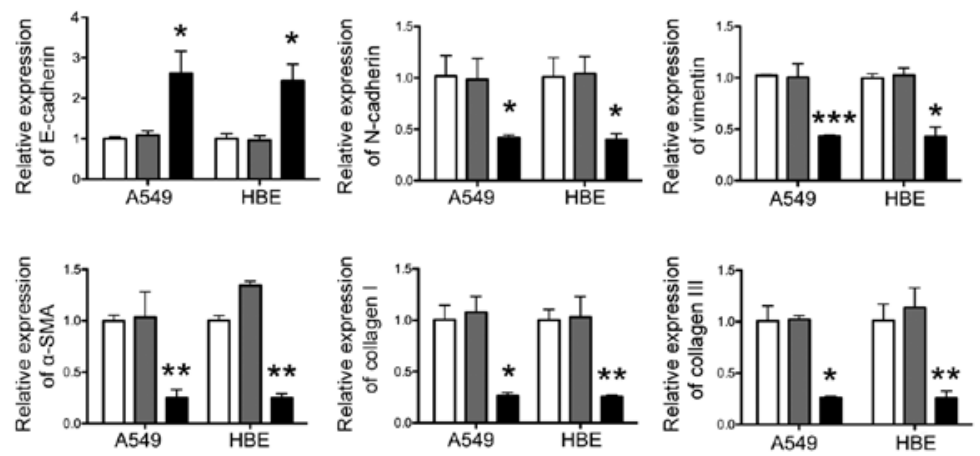

$\mathrm{F}$
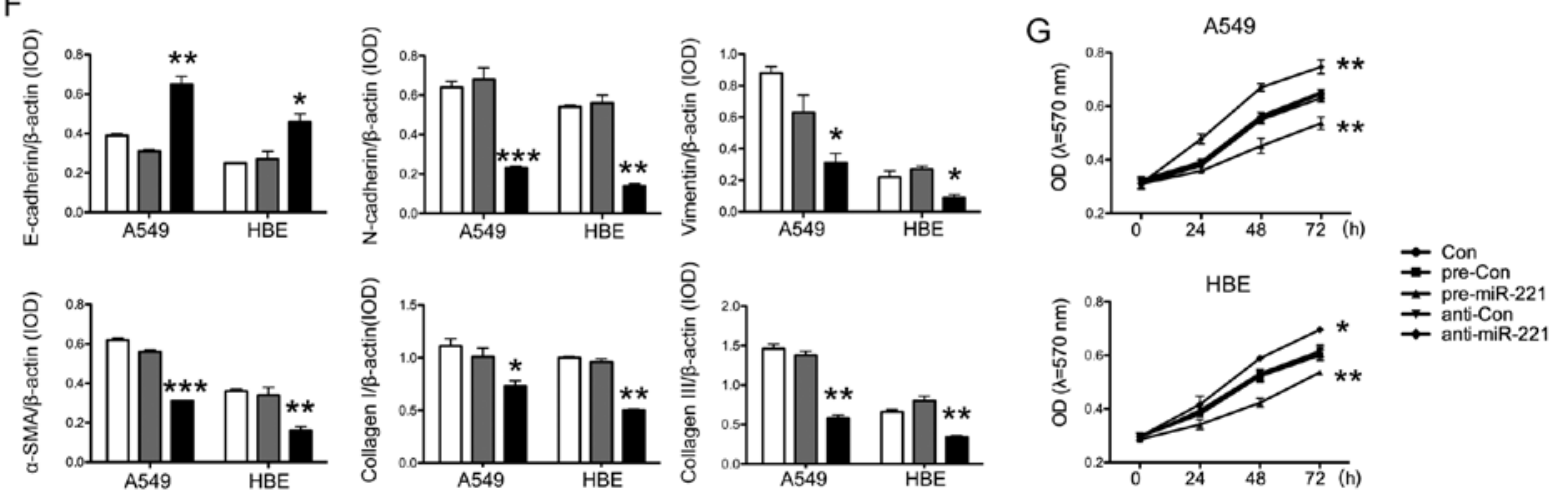

Figure 4. Overexpression of miR-221 downregulates the expression of high mobility group AT-hook 2 (HMGA2), suppresses the epithelial-mesenchymal transition as well as the proliferation of A549 and human bronchial epithelium (HBE) cells. A549 and HBE cells transfected with or without mimics were treated with transforming growth factor- $\beta 1$ (TGF- $\beta 1$ ) for $48 \mathrm{~h}$. Mimics NC was used as the control. (A) The relative expression of HMGA2 in A549 and HBE cells following transfection was detected by qPCR. (B) Representative western blot showing the protein expression of HMGA2 in A549 and HBE cells with or without transfection. (C) Statistical analysis of the protein expression of HMGA2 in A549 and HBE cells. (D) The relative expression of E-cadherin, N-cadherin, vimentin, $\alpha$-smooth muscle actin ( $\alpha$-SMA), collagen I and collagen III in A549 and HBE cells measured by qPCR (E) Representative western blot showing the protein expression of E-cadherin, N-cadherin, vimentin, $\alpha$-SMA, collagen I and collagen III in A549 and HBE cells with or without transfection. (F) Statistical analysis of the protein expression of E-cadherin, N-cadherin, vimentin, $\alpha$-SMA, collagen I and collagen III in A549 and HBE cells. (G) Cellular proliferation was measured in control and miR-221 mimic-transfected A549 (upper) and HBE (lower) cells at 24,48 and $72 \mathrm{~h}$ using the MTT assay. Data are presented as the means $\pm \mathrm{SD}, \mathrm{n}=3$. ${ }^{*} \mathrm{P}<0.05 ;{ }^{* *} \mathrm{P}<0.01 ;{ }^{* * * *} \mathrm{P}<0.001$

miR-221 suppresses BLM-induced pulmonary fibrosis. Firstly, we examined the suppressive effect of miR-221 on lung fibrosis by $\mathrm{H} \&$ E staining. As shown in Fig. 6A, tissues in the control group exhibited a continuous structure with an intact wall of bronchial mucous membrane and normal lung alveoli. However, the BLM and BLM + pre-Con groups had the thickest alveolar walls among all the groups. Furthermore, the lung mesenchyme in the BLM and BLM + pre-Con groups showed strong immunohistochemical staining for collagens and collagen fibers, indicating that the hallmark of the fibroblastic foci was present after BLM treatment. However, these characteristics of lung fibrosis were significantly reduced in the miR-221-treated groups. The tissue sections from miR-221-treated groups had thinner alveolar walls.

Additionally, western blot analysis and qPCR were performed to evaluate the expression of EMT-related proteins. MiR-221 significantly increased E-cadherin expression $(\mathrm{P}=0.021 ; \mathrm{P}=0.002)$, and significantly decreased vimentin $(\mathrm{P}=0.001 ; \mathrm{P}=0.004), \alpha-\mathrm{SMA}(\mathrm{P}=0.005 ; \mathrm{P}=0.005)$, collagen $\mathrm{I}$
$(\mathrm{P}=0.001 ; \mathrm{P}=0.010)$, and collagen III $(\mathrm{P}=0.012 ; \mathrm{P}=0.005)$ compared with BLM group and $\mathrm{BLM}+$ pre-Con group, respectively (Fig. 6B and C). The results of qPCR showed that miR-221 treatment had similar effects as those observed with western blot analysis on the BLM-induced downregulated expression of E-cadherin (compared with BLM, $\mathrm{P}=0.004$, compared with $\mathrm{BLM}+$ pre-Con, $\mathrm{P}=0.001)$ and on the $\mathrm{BLM}$-induced upregulated expression of other EMT-related proteins (vimentin, $\mathrm{P}=0.005$, $\mathrm{P}=0.008 ; \alpha$-SMA, $\mathrm{P}=0.012, \mathrm{P}=0.007$; collagen $\mathrm{I}, \mathrm{P}=0.000$, $\mathrm{P}=0.001$; collagen III, $\mathrm{P}=0.006, \mathrm{P}=0.001$ ) compared with $\mathrm{BLM}$ group and BLM+pre-Con group, respectively (Fig. 6D and E). Collectively, these findings suggest that miR-221 suppressed the EMT in a model of BLM-induced pulmonary fibrosis.

\section{Discussion}

In the present study, we detected the downregulation of miR-221 in human IPF tissues and examined the effects of miR-221 

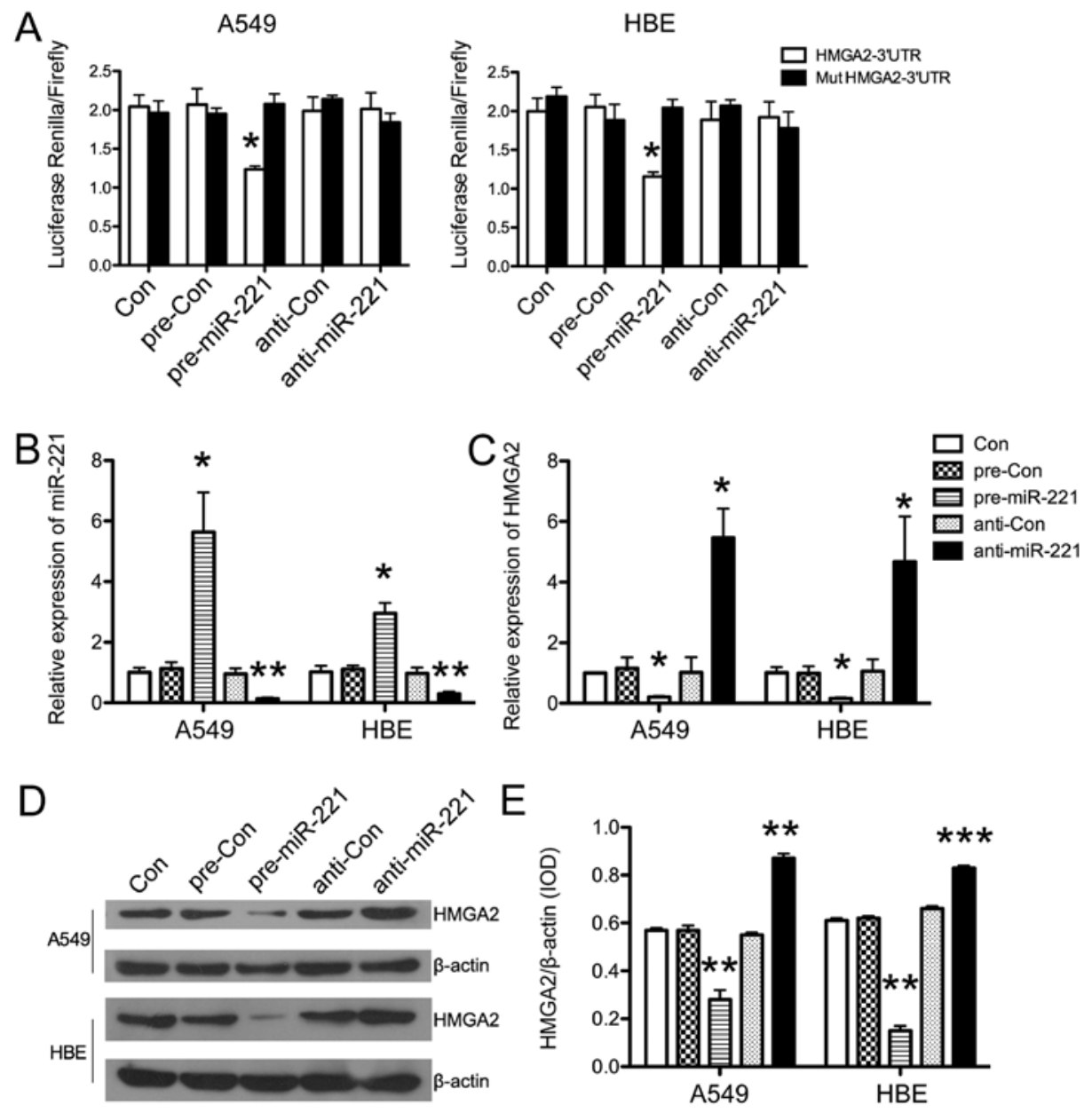

Figure 5. miR-221 directly targets high mobility group AT-hook 2 (HMGA2) and induces the downregulation of HMGA2 in A549 and human bronchial epithelium (HBE) cells. (A) A dual-luciferase reporter gene assay was used to analyze whether miR-221 targets HMGA2. A549 and HBE cells were transfected with HMGA2-3'-UTR, combined with miR-221 or miR-221-inhibitor or the negative controls. At $24 \mathrm{~h}$ after transfection, the cells were lysed and the activity of both Renilla and firefly luciferase was assayed by the dual-luciferase reporter gene system. Bars represent the mean values $\pm \mathrm{SD}$. ${ }^{*} \mathrm{P}<0.05, \mathrm{n}=3$ for each group. (B) The relative expression of miR-221 in cells transfected with pre-miR-221 or anti-miR-221. (C) The relative expression of HMGA2 in cells transfected with pre-miR-221 or anti-miR-221. (D) Representative western blot showing the protein expression of HMGA2 in A549 and HBE cells transfected with pre-miR-221 or anti-miR-221. (E) Statistical analysis of HMGA2 protein expression by western blot analysis in cells transfected with pre-miR-221 or anti-miR-221. Bars represent the mean values $\pm \mathrm{SD}, \mathrm{n}=3 .{ }^{*} \mathrm{P}<0.05 ;{ }^{* *} \mathrm{P}<0.01 ;{ }^{* * * *} \mathrm{P}<0.001$; compared with the Con group.

on pulmonary fibrosis as well as the mechanisms responsible for these effects. Our results indicated that TGF- $\beta 1$ reduced the expression of miR-221 and upregulated the expression of HMGA2 in A549 and HBE cells as well as upregulating the expression of EMT-related proteins. Additionally, the overexpression of miR-221 in cells impaired the EMT induced by TGF- $\beta 1$, which is mediated by directly targeting HMGA2. miR-221 also impaired the EMT in a model of BLM-induced pulmonary fibrosis.

BLM is an antineoplastic agent that causes fibrosis as a prominent side effect. BLM-induced pulmonary fibrosis is the most commonly used model of IPF for studying disease pathogenesis and for testing novel pharmaceutical compounds (28).

BLM-induced lung injury is characterized by inflammation followed by apoptosis of epithelial and endothelial cells, mesenchymal cell proliferation and the deposition of extracellular matrix resulting in the destruction of the lung architecture and the progressive loss of pulmonary function (29). However, different strains of mice show different sensitivities to BLM. For example, BLM-sensitive mice injured with BLM showed significant increases in miR-155 expression compared with the
BLM-resistant BALB/c strain (30). Using a single mouse strain may be a potential limitation of our study. Even so, the fact that many miRNAs and genes found in mice have molecular and functional homologues in vertebrates, including humans, means that genetic discoveries in animal models may be generalizable to our understanding of IPF and assist in the identification of potential therapies for this challenging disease (30).

miRNAs are reportedly associated with pulmonary fibrosis (20). Members of the miR-200 family and miR-205 are decreased when cells undergo EMT (17). miR-124 targets Slug to regulate EMT and to promote the metastasis of breast cancer (18). The increased expression of miR-155 has been demonstrated in a mouse model of lung fibrosis (19). Liu et al showed that mice with BLM-induced pulmonary fibrosis exhibited a significant increase in miR-21 levels, which was associated with increased TGF- $\beta$ levels (20). Furthermore, the expression of members of the miR-29 family was decreased in the lungs of patients with IPF compared with that in normal individuals (21). miR-221 is also associated with organ fibrosis. It has been reported that miR-221 was downregulated in fibrotic kidneys after unilateral ureteral occlusion (31). The 

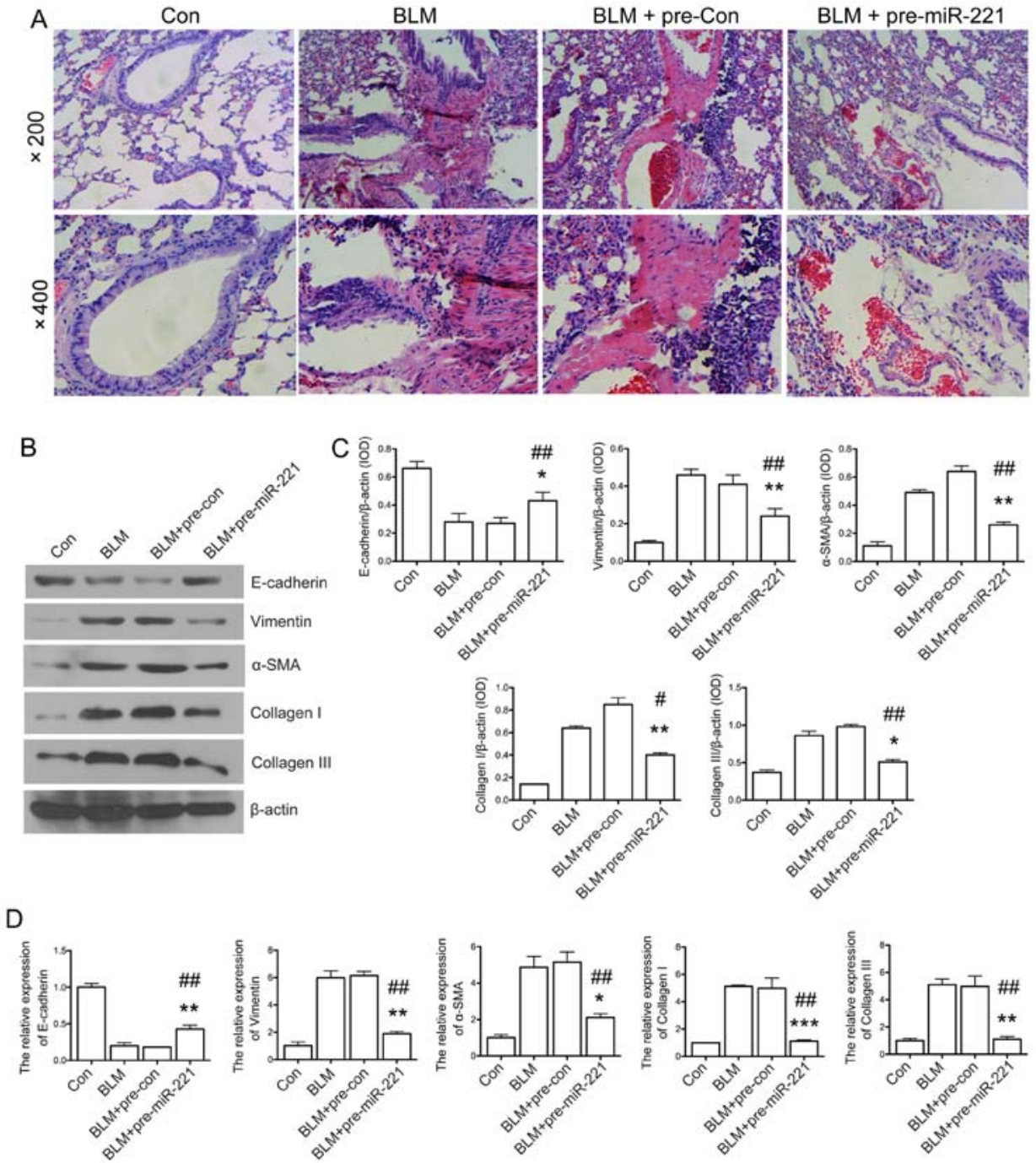

Figure 6. miR-221 suppresses the epithelial-mesenchymal transition in a mouse model of bleomycin (BLM)-induced pulmonary fibrosis. (A) Representative images of hematoxylin and eosin-stained lung tissue in a model of BLM-induced pulmonary fibrosis with or without mimic injection. Upper panels, x200 magnification; lower panels, x400 magnification. (B) Representative western blot showing the protein expression of E-cadherin, vimentin, $\alpha$-smooth muscle actin ( $\alpha$-SMA), collagen I, and collagen III in a model of BLM-induced pulmonary fibrosis with or without mimic injection. (C) Statistical analysis of the protein expression of E-cadherin, vimentin, $\alpha$-SMA, collagen I, and collagen III in an animal model of pulmonary fibrosis. (D) The relative expression of E-cadherin, vimentin, $\alpha$-SMA, collagen I and collagen III in a model of BLM-induced pulmonary fibrosis was measured by qPCR. Animals without BLM treatment were used as the control group. Data are presented as means \pm standard deviation, $n=3$. $P<0.05,{ }^{* *} \mathrm{P}<0.01$ and ${ }^{* * * *} \mathrm{P}<0.001$ compared with BLM group. ${ }^{\#} \mathrm{P}<0.05$ and ${ }^{\# \#} \mathrm{P}<0.01$ compared with BLM + pre-Con group.

expression of miR-221/222 also increased with the progression of liver fibrosis, and significantly correlated with the mRNA expression of collagen I and $\alpha$-SMA in human fibrotic livers (26). Notably, Lino Cardenas et al reported that miR-221 is downregulated in a model of BLM-induced pulmonary fibrosis by miRNA expression profiling (30). Furthermore, tissue microarray analysis of IPF tissues has also confirmed the downregulation of miR-221. In the present study, we focused on the effects of miR-221 on pulmonary fibrosis as well as the mechanisms responsible for these effects.

EMT is a process in which epithelial cells lose their epithelial phenotype, acquire fibroblast-like properties, and display reduced cell adhesion and increased motility. In our study, E-cadherin was used as an epithelial marker, and $\mathrm{N}$-cadherin, vimentin and $\alpha$-SMA were used as mesenchymal markers. They were all used to estimate the EMT condition, in combination with the analysis of collagen I/III deposition. miR-221 led to the upregulation of E-cadherin and the downregulation of $\mathrm{N}$-cadherin, vimentin and
$\alpha$-SMA. In other words, miR-221 inhibited the EMT process in pulmonary fibrosis. This finding differs from some previous studies. Stinson et al demonstrated that adding miR-221/222 results in a decrease in E-cadherin and increase in vimentin that is consistent with an EMT in breast cancer (32). Liu et al reported that miR-221 facilitates the TGF- $\beta 1$-induced EMT in human bladder cancer cells by targeting STMN1 (24). In addition, miR-221/222 has been found target adiponectin receptor 1 to promote the EMT in breast cancer (23). These findings may be due to the fact that miR-221 targets different downstream receptors to induce different effects on EMT.

HMGA2 is a transcription factor that is induced by the TGF- $\beta 1 /$ Smad3 signaling pathway during the EMT process (3). It has been reported that miRNA let-7d (33), miR-33b (34), miR-15, miR-16, miR-26 and miR-196a-2 $(35,36)$ all target HMGA to regulate EMT. In this study, for the first time to the best of our knowledge, we confirmed that HMGA2 is a direct target of miR-221. This finding is important as it enhances our 
understanding of the role of miR-221 in BLM-induced EMT and pulmonary fibrosis.

In conclusion, miR-221 inhibits the EMT process in BLM-induced pulmonary fibrosis through the TGF- $\beta 1 / \mathrm{Smad} 3$ signaling pathway, and HMGA2 is the direct target of miR-221. These findings may provide novel insights into the pathogenesis of IPF. In addition, as miRNAs have multiple targets, the therapeutic manipulation of miRNA may have multiplicative effects on gene expression and on the fibrotic phenotype in the lung, which warrants further investigation by our group.

\section{References}

1. Selman M, Pardo A and Kaminski N: Idiopathic pulmonary fibrosis: aberrant recapitulation of developmental programs? PLoS Med 5: e62, 2008.

2. Song X, Liu W, Xie S, Wang M, Cao G, Mao C and Lv C: All-transretinoic acid ameliorates bleomycin-induced lung fibrosis by downregulating the TGF- $\beta 1 /$ Smad3 signaling pathway in rats. Lab Invest 93: 1219-1231, 2013.

3. Pandit KV, Corcoran D, Yousef H, Yarlagadda M, Tzouvelekis A, Gibson KF, Konishi K, Yousem SA, Singh M, Handley D, et al: Inhibition and role of let-7d in idiopathic pulmonary fibrosis. Am J Respir Crit Care Med 182: 220-229, 2010.

4. Kriz W, Kaissling B and Le Hir M: Epithelial-mesenchymal transition (EMT) in kidney fibrosis: fact or fantasy? J Clin Invest 121: 468-474, 2011.

5. Willis BC,Liebler JM, Luby-Phelps K, Nicholson AG, Crandall ED, du Bois RM and Borok Z: Induction of epithelial-mesenchymal transition in alveolar epithelial cells by transforming growth factor-beta1: potential role in idiopathic pulmonary fibrosis. Am J Pathol 166: 1321-1332, 2005.

6. Kalluri R and Weinberg RA: The basics of epithelial-mesenchymal transition. J Clin Invest 119: 1420-1428, 2009.

7. Hu WQ, Wang LW, Yuan JP, Yan SG, Li JD, Zhao HL, Peng CW, Yang GF and Li Y: High expression of transform growth factor beta 1 in gastric cancer confers worse outcome: results of a cohort study on 184 patients. Hepatogastroenterology 61: 245-250, 2014.

8. Vincent T, Neve EP, Johnson JR, Kukalev A, Rojo F, Albanell J, Pietras K, Virtanen I, Philipson L, Leopold PL, et al: A SNAIL1-SMAD3/4 transcriptional repressor complex promotes TGF-beta mediated epithelial-mesenchymal transition. Nat Cell Biol 11: 943-950, 2009.

9. Sime PJ, Marr RA, Gauldie D, Xing Z, Hewlett BR, Graham FL and Gauldie J: Transfer of tumor necrosis factor-alpha to rat lung induces severe pulmonary inflammation and patchy interstitial fibrogenesis with induction of transforming growth factor-beta1 and myofibroblasts. Am J Pathol 153: 825-832, 1998.

10. Serini G and Gabbiani G: Mechanisms of myofibroblast activity and phenotypic modulation. Exp Cell Res 250: 273-283, 1999.

11. Schürch W, Seemayer TA and Gabbiani G: The myofibroblast: a quarter century after its discovery. Am J Surg Pathol 22 141-147, 1998.

12. Munger JS, Huang X, Kawakatsu H, Griffiths MJ, Dalton SL, Wu J, Pittet JF, Kaminski N, Garat C, Matthay MA, et al: The integrin alpha $\mathrm{v}$ beta 6 binds and activates latent TGF beta 1: a mechanism for regulating pulmonary inflammation and fibrosis. Cell 96: 319-328, 1999.

13. D'Alessandro-Gabazza CN, Kobayashi T, Boveda-Ruiz D, Takagi T, Toda M, Gil-Bernabe P, Miyake Y, Yasukawa A, Matsuda Y, Suzuki N, et al: Development and preclinical efficacy of novel transforming growth factor- $\beta 1$ short interfering RNAs for pulmonary fibrosis. Am J Respir Cell Mol Biol 46: 397-406, 2012.

14. Dong XS, Hu XB, Liu W, Sun YQ and Liu Z: Effects of RNA interference-induced $\mathrm{Smad} 3$ gene silencing on pulmonary fibrosis caused by paraquat in mice. Exp Biol Med (Maywood) 237: 548-555, 2012.

15. Xiao J, Meng XM, Huang XR, Chung AC, Feng YL, Hui DS, Yu CM, Sung JJ and Lan HY: miR-29 inhibits bleomycin-induced pulmonary fibrosis in mice. Mol Ther 20: 1251-1260, 2012.

16. Roush S and Slack FJ: The let-7 family of microRNAs. Trends Cell Biol 18: 505-516, 2008.

17. Gregory PA, Bert AG, Paterson EL, Barry SC, Tsykin A, Farshid G, Vadas MA, Khew-Goodall Y and Goodall GJ: The miR-200 family and miR-205 regulate epithelial to mesenchymal transition by targeting ZEB1 and SIP1. Nat Cell Biol 10: 593-601, 2008.
18. Liang YJ, Wang QY, Zhou CX, Yin QQ, He M, Yu XT, Cao DX, Chen GQ, He JR and Zhao Q: MiR-124 targets Slug to regulate epithelial-mesenchymal transition and metastasis of breast cancer. Carcinogenesis 34: 713-722, 2013.

19. Pottier N, Maurin T, Chevalier B, Puisségur MP, Lebrigand K, Robbe-Sermesant K, Bertero T, Lino Cardenas CL, Courcot E, Rios G, et al: Identification of keratinocyte growth factor as a target of microRNA-155 in lung fibroblasts: implication in epithelial-mesenchymal interactions. PLoS One 4: e6718, 2009.

20. Liu G, Friggeri A, Yang Y, Milosevic J, Ding Q, Thannickal VJ, Kaminski N and Abraham E: miR-21 mediates fibrogenic activation of pulmonary fibroblasts and lung fibrosis. J Exp Med 207: 1589-1597, 2010.

21. Cushing L, Kuang P and Lü J: The role of miR-29 in pulmonary fibrosis. Biochem Cell Biol 93: 109-118, 2015.

22. Su A, He S, Tian B, Hu W and Zhang Z: MicroRNA-221 mediates the effects of PDGF-BB on migration, proliferation, and the epithelial-mesenchymal transition in pancreatic cancer cells. PLoS One 8: e71309, 2013.

23. Hwang MS, Yu N, Stinson SY, Yue P, Newman RJ, Allan BB and Dornan D: miR-221/222 targets adiponectin receptor 1 to promote the epithelial-to-mesenchymal transition in breast cancer. PLoS One 8: e66502, 2013.

24. Liu J,Cao J and Zhao X: miR-221 facilitates the TGFbeta1-induced epithelial-mesenchymal transition in human bladder cancer cells by targeting STMN1. BMC Urol 15: 36, 2015.

25. Glowacki F, Savary G, Gnemmi V, Buob D, Van der Hauwaert C, Lo-Guidice JM, Bouyé S, Hazzan M, Pottier N, Perrais M, et al: Increased circulating miR-21 levels are associated with kidney fibrosis. PLoS One 8: e58014, 2013.

26. Ogawa T, Enomoto M, Fujii H, Sekiya Y, Yoshizato K, Ikeda K and Kawada N: MicroRNA-221/222 upregulation indicates the activation of stellate cells and the progression of liver fibrosis. Gut 61: 1600-1609, 2012.

27. Hecker L, Vittal R, Jones T, Jagirdar R, Luckhardt TR, Horowitz JC, Pennathur S, Martinez FJ and Thannickal VJ: NADPH oxidase-4 mediates myofibroblast activation and fibrogenic responses to lung injury. Nat Med 15: 1077-1081, 2009 .

28. Moeller A, Ask K, Warburton D, Gauldie J and Kolb M: The bleomycin animal model: a useful tool to investigate treatment options for idiopathic pulmonary fibrosis? Int J Biochem Cell Biol 40: 362-382, 2008

29. Weiss DJ, Strandjord TP, Liggitt D and Clark JG: Perflubron enhances adenovirus-mediated gene expression in lungs of transgenic mice with chronic alveolar filling. Hum Gene Ther 10: 2287-2293, 1999

30. Lino Cardenas CL, Kaminski N and Kass DJ: Micromanaging microRNAs: using murine models to study microRNAs in lung fibrosis. Drug Discov Today Dis Models 10: e145-e151, 2013.

31. Di J, Jiang L, Zhou Y, Cao H, Fang L, Wen P, Li X, Dai C and Yang J: Ets-1 targeted by microrna-221 regulates angiotensin II-induced renal fibroblast activation and fibrosis. Cell Physiol Biochem 34: 1063-1074, 2014.

32. Stinson S, Lackner MR, Adai AT, Yu N, Kim HJ, O'Brien C, Spoerke J, Jhunjhunwala S, Boyd Z, Januario T, et al: miR-221/222 targeting of trichorhinophalangeal 1 (TRPS1) promotes epithelial-to-mesenchymal transition in breast cancer. Sci Signal 4: pt5, 2011.

33. Liu Q, Liu T, Zheng S, Gao X, Lu M, Sheyhidin I and Lu X: HMGA2 is down-regulated by microRNA let-7 and associated with epithelial-mesenchymal transition in oesophageal squamous cell carcinomas of Kazakhs. Histopathology 65: 408-417, 2014.

34. Zhang P, Bai H, Liu G, Wang H, Chen F, Zhang B, Zeng P, Wu C, Peng C, Huang C, et al: MicroRNA-33b, upregulated by EF24, a curcumin analog, suppresses the epithelial-to-mesenchymal transition (EMT) and migratory potential of melanoma cells by targeting HMGA2. Toxicol Lett 234: 151-161, 2015.

35. De Martino I, Visone R, Fedele M, Petrocca F, Palmieri D, Martinez Hoyos J, Forzati F, Croce CM and Fusco A: Regulation of microRNA expression by HMGA1 proteins. Oncogene 28: 1432-1442, 2009

36. Kaddar T, Rouault JP, Chien WW, Chebel A, Gadoux M, Salles G, Ffrench M and Magaud JP: Two new miR-16 targets: caprin-1 and HMGA1, proteins implicated in cell proliferation. Biol Cell 101: 511-524, 2009. 